
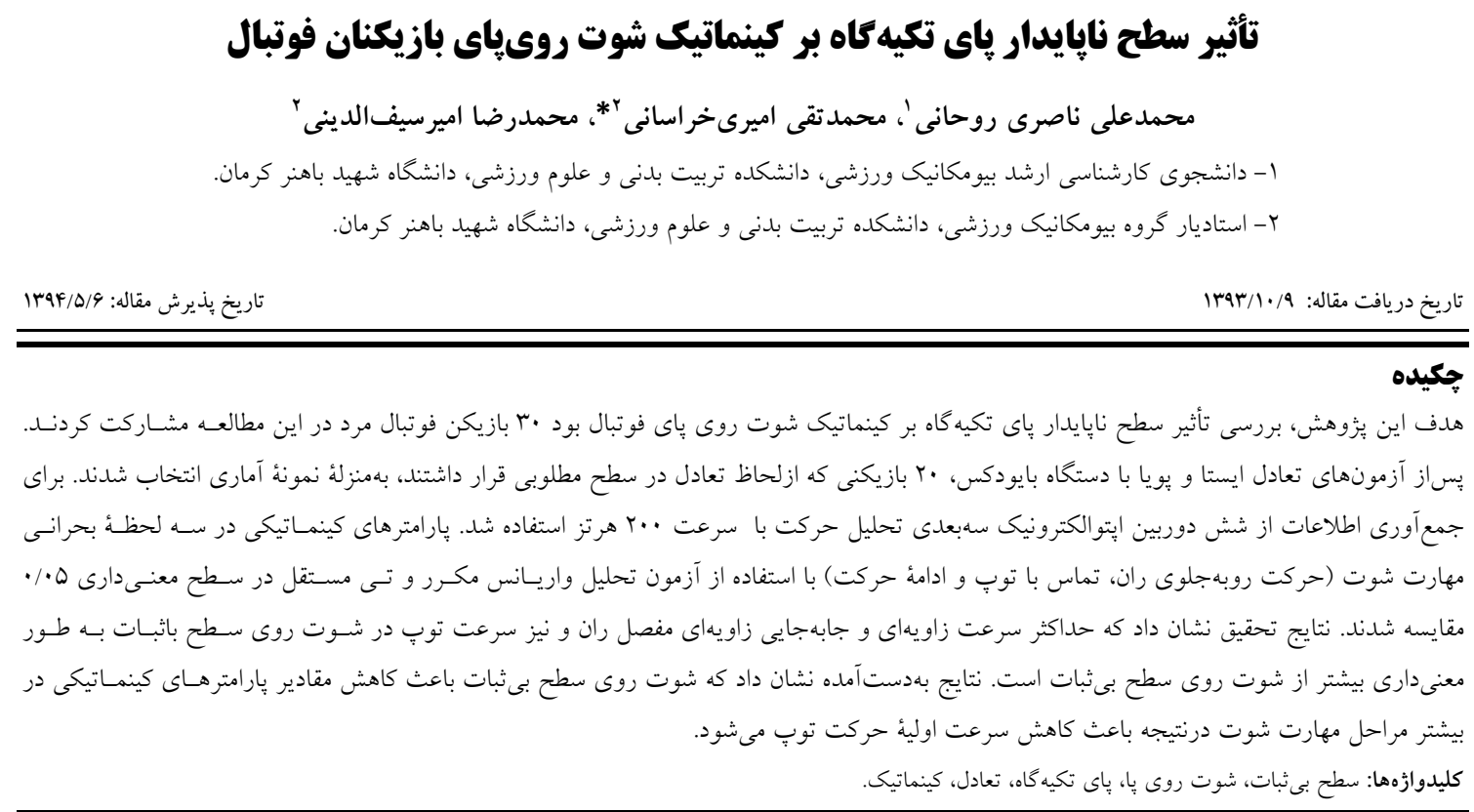

\title{
The effect of non-stability surface of support leg on the instep kicking kinematics in soccer players
}

Naseri-Rohani, M.A' ${ }^{1}$, Amiri-Khorasani, M.T²., AmirSeyfaddini, M.R ${ }^{2}$.

1- Master of Science Sport Biomechanic, Faculty of Physical Education and Sport Sciences, Shahid Bahonar University of Kerman, Iran.

2- Assistant Professor Sport Biomechanic, Faculty of Physical Education and Sport Sciences, Shahid Bahonar University of Kerman, Iran.

\section{Abstract}

Objective: The aim of this study was to investigate the effect of non- stability surface of support leg on the instep kicking kinematics in soccer players. Materials and Methods: 30 male soccer players participated in this study. After the measurement of static and dynamic balance tests by the Biodex System, 20 players were selected who were at a desired level of the balance. Data were recorded using the threedimensional motion analysis system with 6 optoelectronic cameras $(200 \mathrm{HZ})$. The kinematic parameters in three critical moments of kicking (Forward swing of hip, Contact to ball, Follow through) were compared by using repeated measures of variance and independent t- test (0/05). Results: The results showed that the values of maximum angular velocity and displacement of hip and velocity of ball at the kicking over stability surface was significantly higher from the kicking over non- stability surface. Conclusion: These results indicate that the kicking over non- stability surface causes the lower of kinematic parameters in the more of the kicking skill phases and the movement prime velocity of ball.

Keywords: Non- stability surface, Instep kicking, Support leg, Balance, Kinematics.

\footnotetext{
*. amirikhorasani@uk.ac.ir.
} 


\section{مقدمه}

فوتبال ' ورزشى تويى است كه به مهارتهاى تكنيكى و تـاكتيكى بسـيار زيـاد بازيكنـان نيـاز دارد. يكى از مهمترين مهارت هاى بازيكنان فوتبال، اجراى شوت در زمان حمله يا زمان ضربههاى ينالتى است كه بارهـا در بازى رخ مىدهد. شوت فوتبال انواع مختلفى دارد كه ازميان آنها، شوت روى يا بهدليل دقت و سـرعت زيـاد كاربرد فراوانى در بازى دارد (ه-1). بهطور كلى، بهدليل نوع جنس تـوبٍ، سـرعت و موقعيـتهــاى مختلـف

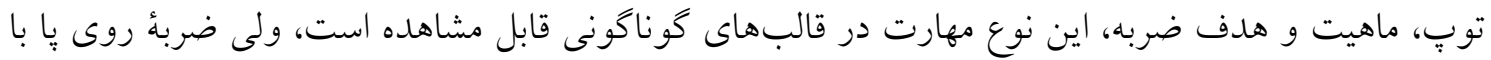
حداكثر سرعت به توب ساكن، يكى از مهمترين و كليـدىتـرين شـوتهاى فوتبـال اسـت كـه در تحقيقـات كذشته نيز بيشتر به آن برداخته شده است (• (1-9). موفقيت شوت فوتبال به عوامل مختلفى وابسته اسـت كـهـ

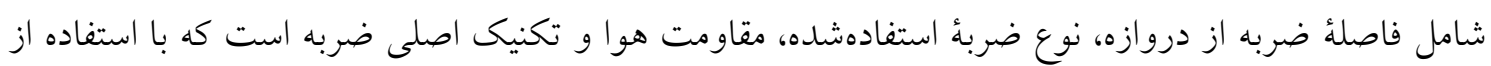

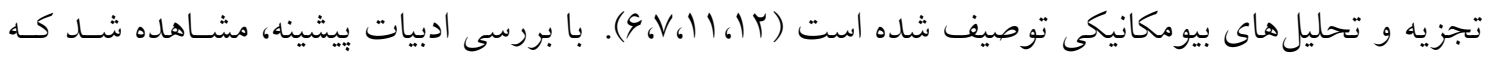

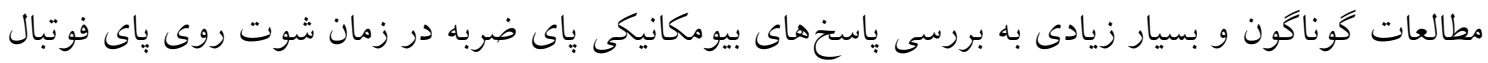

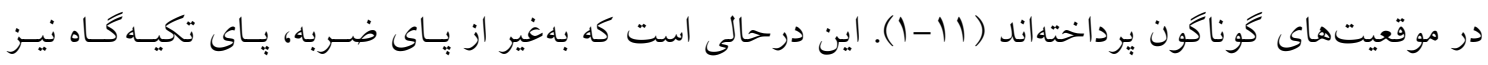
مى تواند نقش كليدى در طول اجراى شوت روى ياى فوتبال بازى كند (سا، Y ()). بسيارى از بازيكنان فوتبـال،

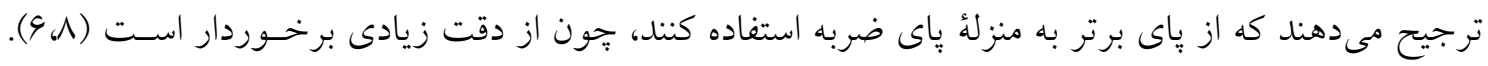

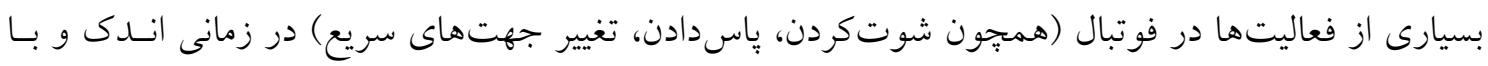

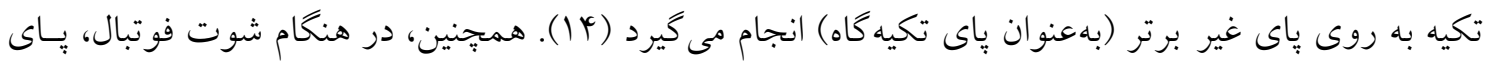

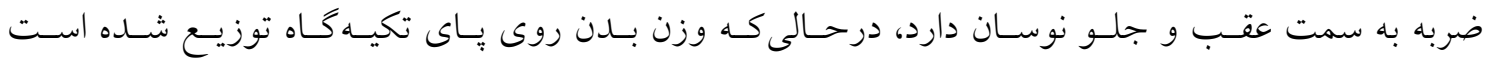

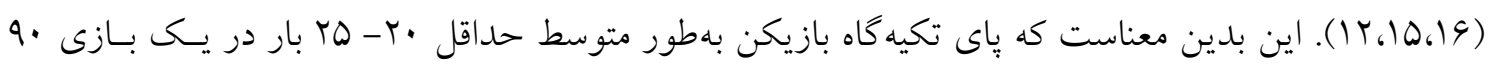

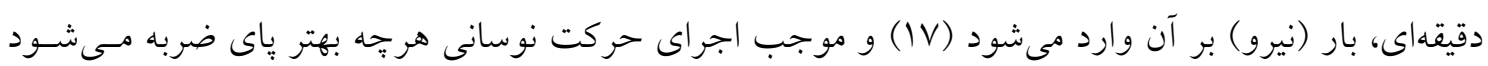

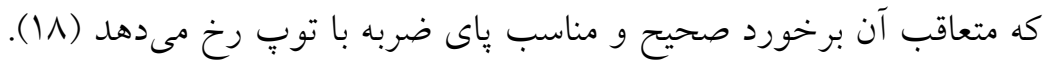

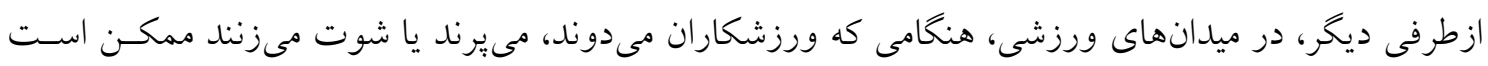

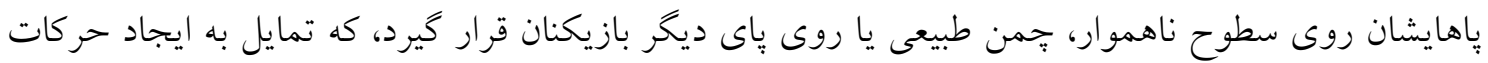

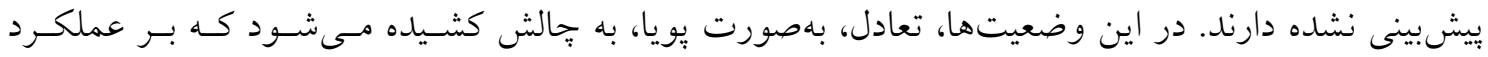
مهارت شوت مؤثر است (19). ازطرفى، شوت فوتبال به كنترل و بهرهورى از نيروهاى بسيار زيادى نياز دارد،

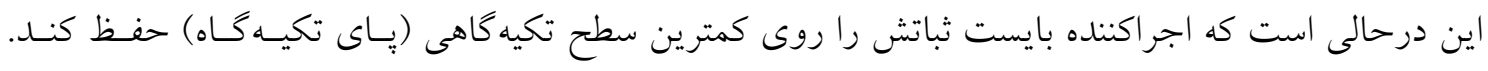
بسيارى از محققان بيان كردند كه تعادل بيشنياز اساسى موفقيت در اجراهاى ورزشى اسـت و بــراى اجـراى مهارتها و عملكردهاى حركتى اساسى، همانند برش، سرخوردن، يرتابكردن و شوت كردن (فوتبـال) بسـيار

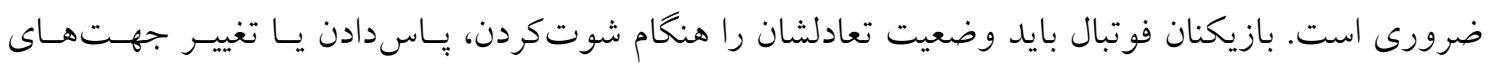

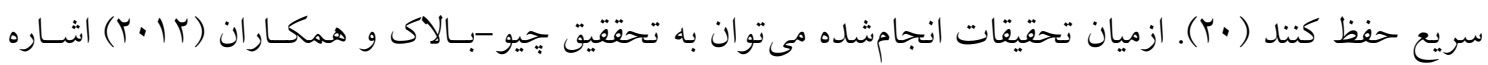


كرد كه به رابطهُ عملكرد شوت با توانيى تعادل روى يّاى تكيه كاه برداختند. آنها نشان دادنـــ كـهـ بـين ميـزان

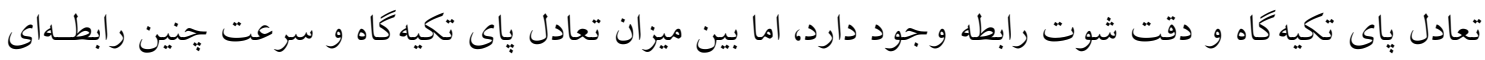

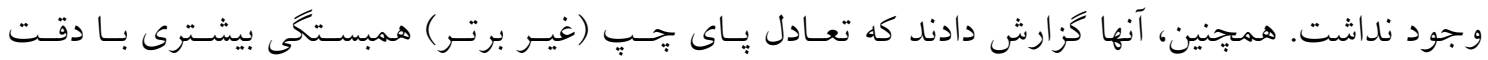

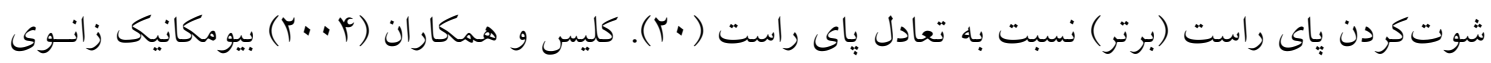

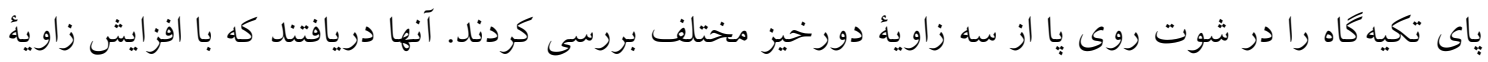

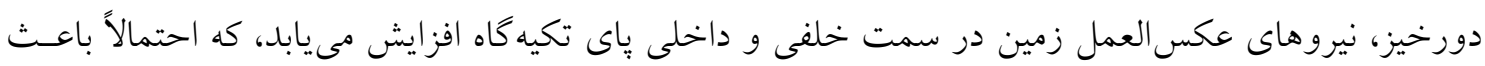

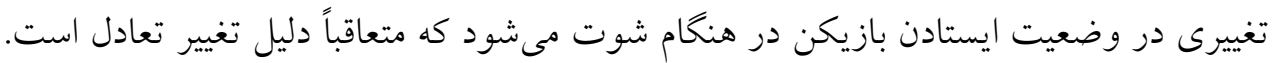

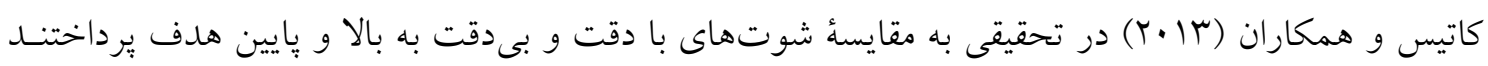
و يى بردند كه نيروهاى عكسالعمل زمين باى تكيه كاه هيج تفاوتى بين وضعيتهاى شـوت ايجـاد نمسى كنتسد

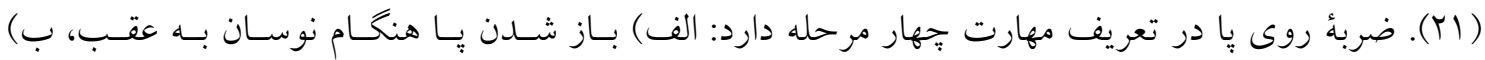

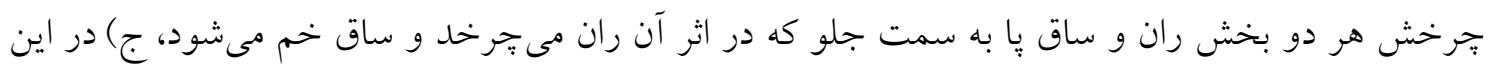

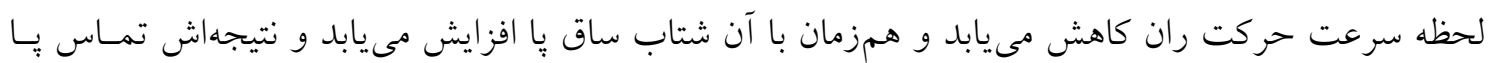

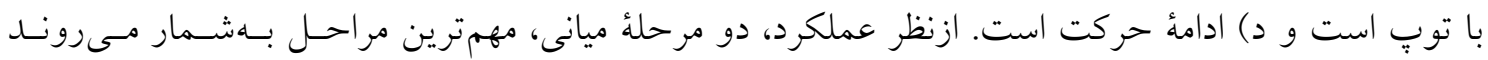

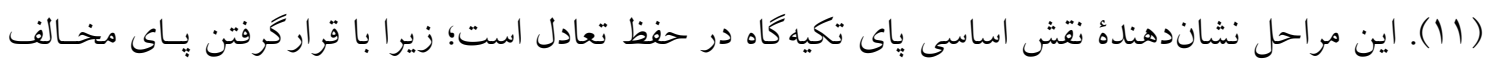

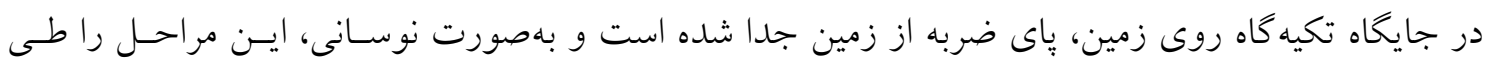

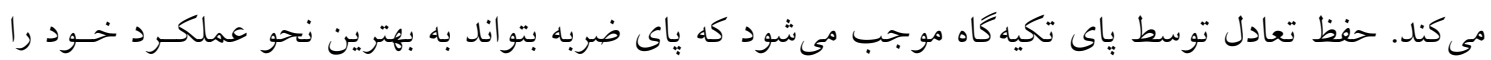

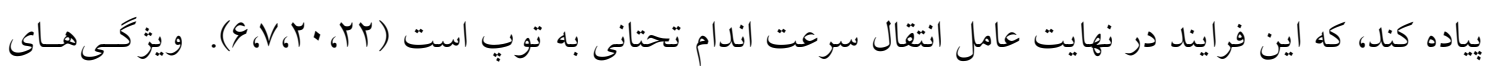

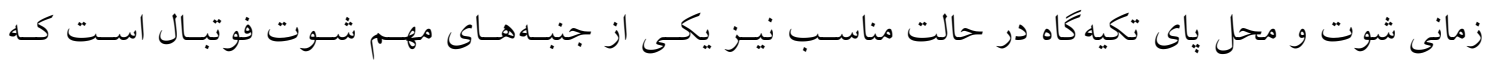

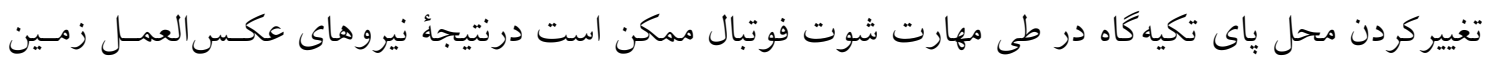

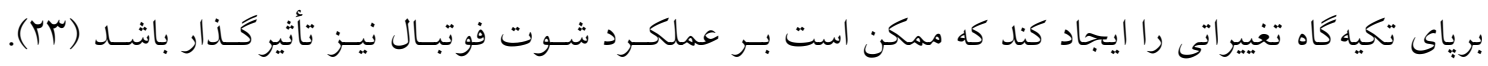

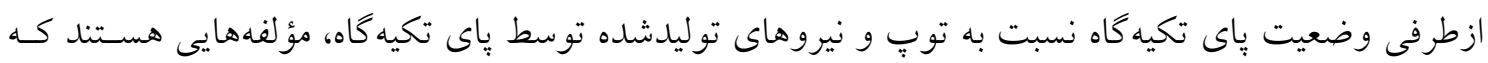

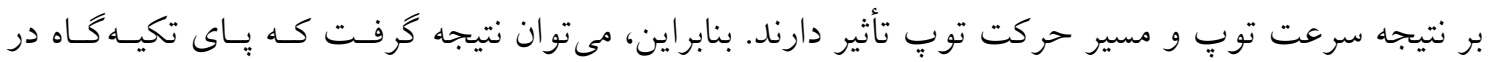

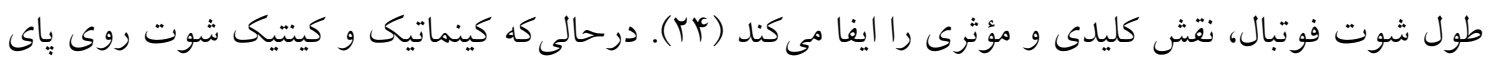
فوتبال به طور كستردهاى بررسى شده است و براساس اهميت ذكرشده، تحقيقات انـدكى دربــارهُ رابطـــ بــين

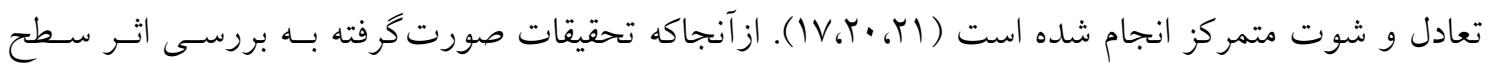

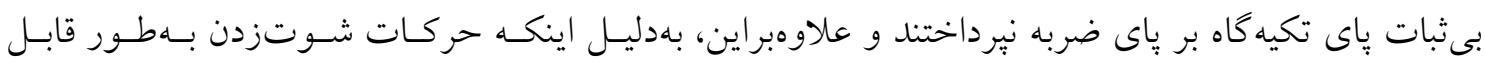

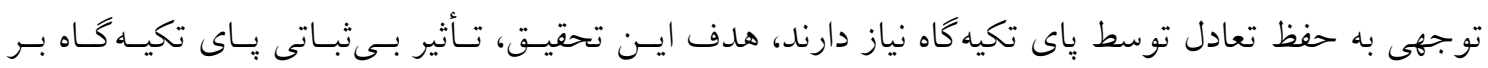
كينماتيك شوت روى بِى فوتبال است. 


\section{روششناسى}

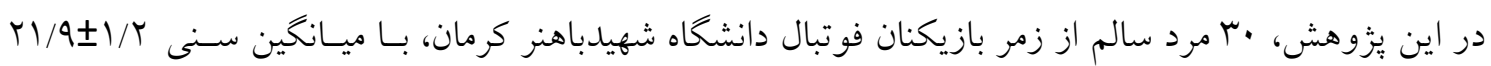

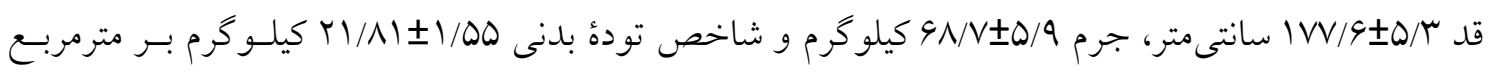

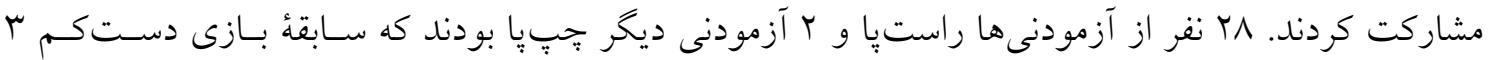

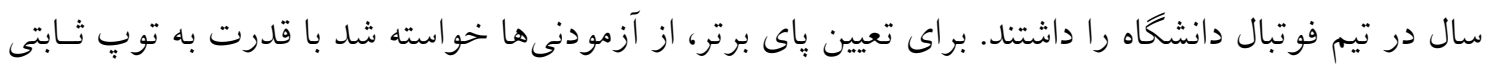

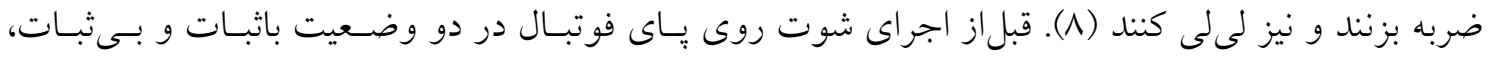

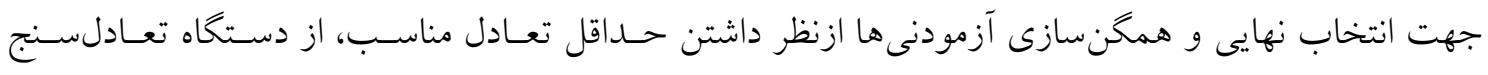
بايودكس (BBS)' براى سنجش تعادل و شاخصهاى تعادل بازيكنان فوتبال استفاده شد كـهـ روايسى و پِيـايى

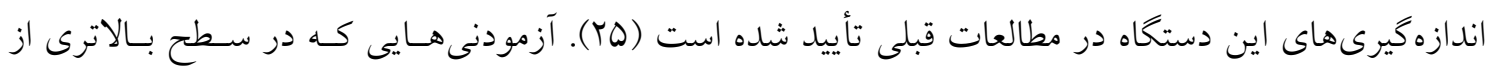

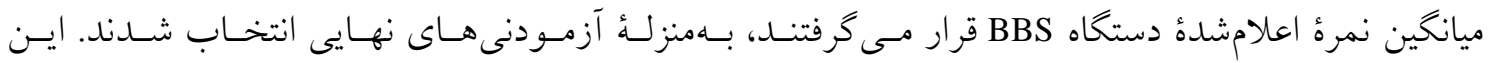
آزمودنى ها داوطلبانى بودند كه بالاترين نمره را در حفظ تعادل از خود بهجـا كذاشـتند. در ابتـدا، توضسيحات

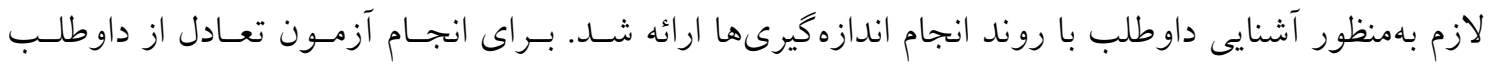

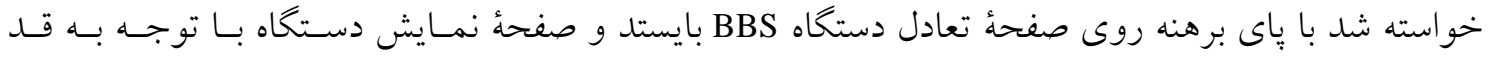

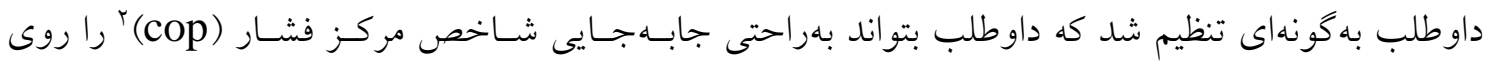

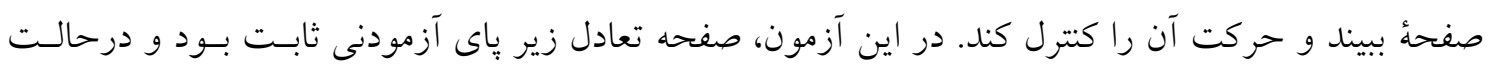

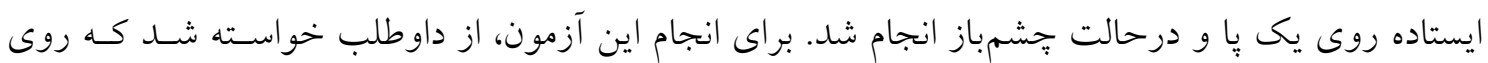

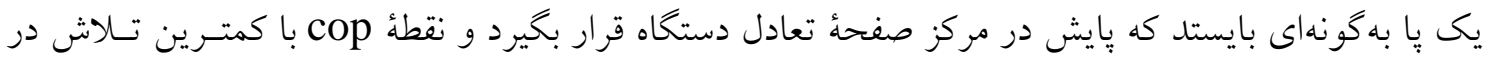

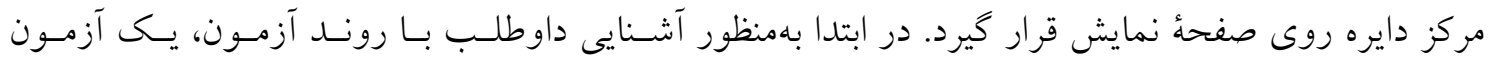

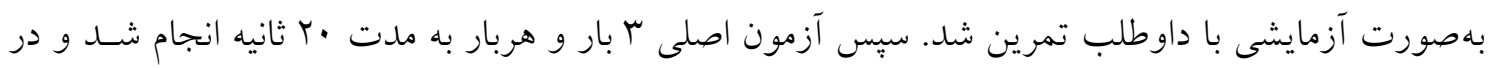

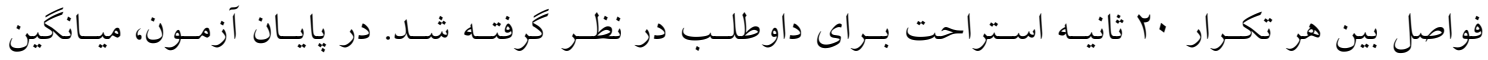

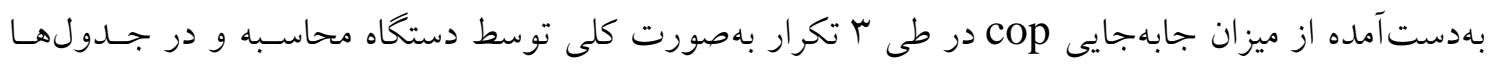

ثبت مىشد (TO)

براى انجام آزمون تعادل يويا، از داوطلب خواسته شد كه روى يك يا بر مركز صفحهُ دستكاه BBS كـه سـاكن

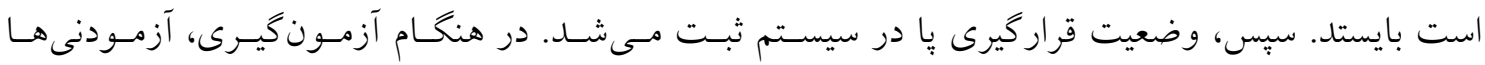

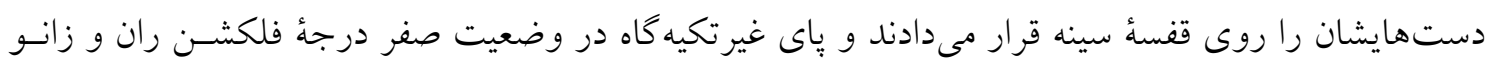

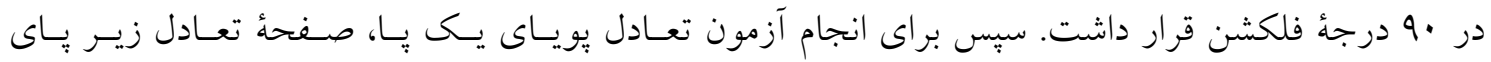

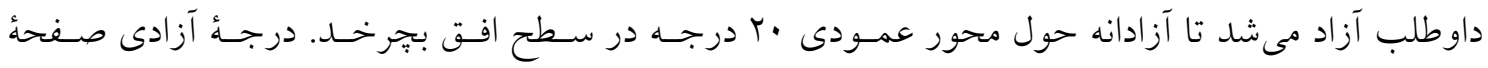

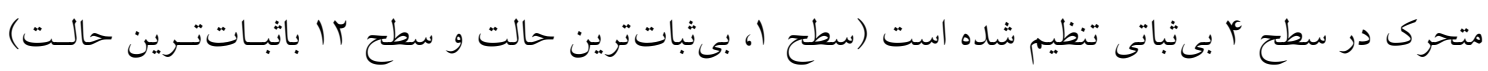

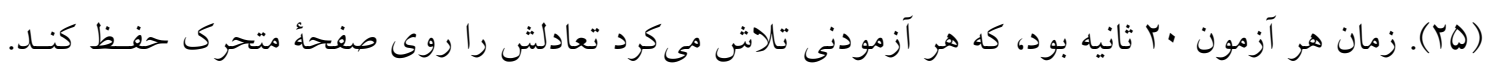

1. Biodex Balance System

2. Center of Pressure 


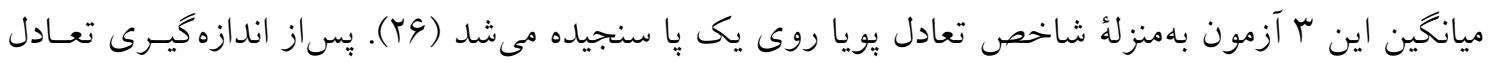

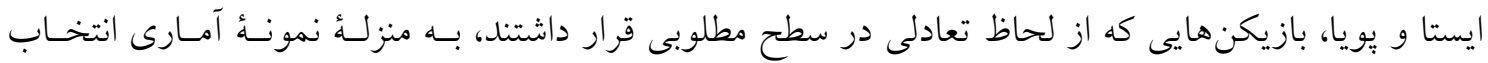

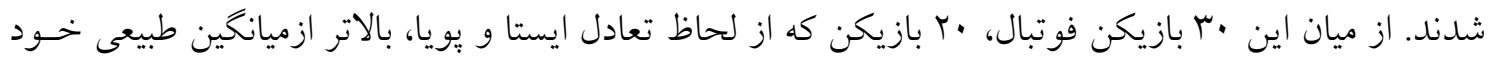

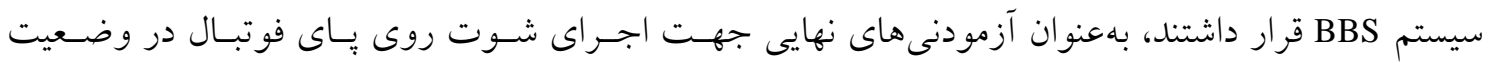
باثبات و بىثباتى انتخاب شدند. از آنجاكه جمع آورى دادهها بهصورت كانتربالانس بود، اين تعداد آزمودنى بـراى ايسن

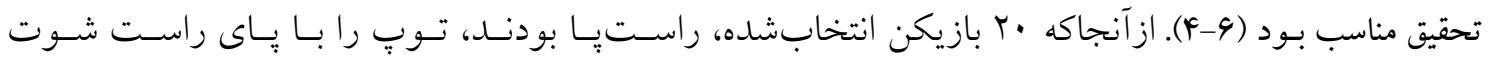

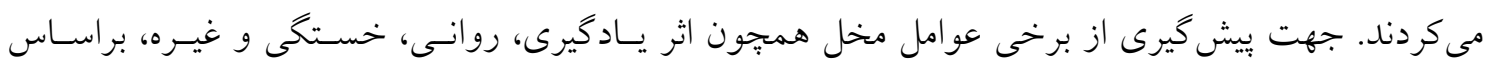

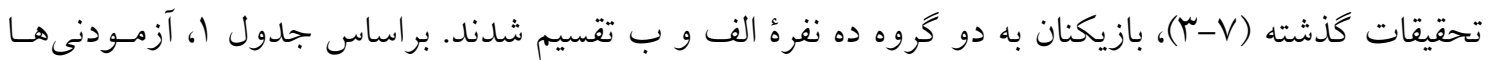
طى دو روز غيرمتو الى، اقدام به شوت روى يا كردند.

جدول ا. يروتكل اجرايى شوت روى يا توسط بازيكنان فو تبال

\begin{tabular}{|c|c|c|}
\hline روز دوم & روز اول & كرون \\
\hline شوت در شرايط بىثبات & شوت در شرايط باثبات & الف الف \\
\hline شوت در شرايط باثبات & شوت در شرايط بىثبات & ب ب \\
\hline
\end{tabular}

يساز گرمكردن در مدت ه دقيقه كه نرمدويدن و حركات كششى بود، 9 نشانگر كروى بـه انسام تحتـانى، در

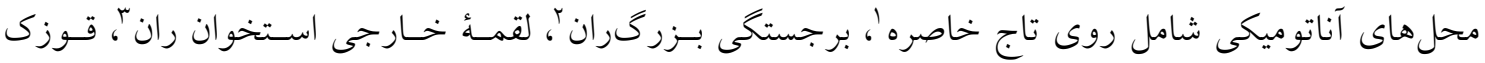

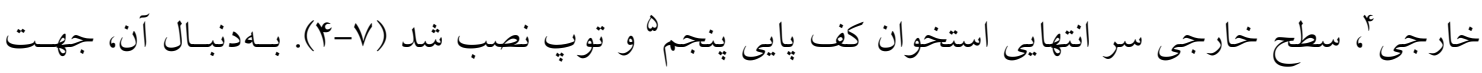

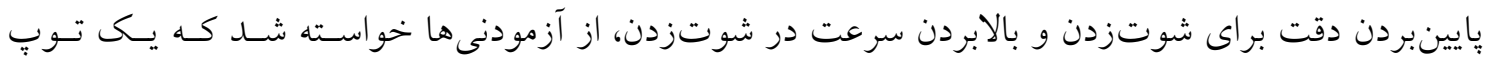

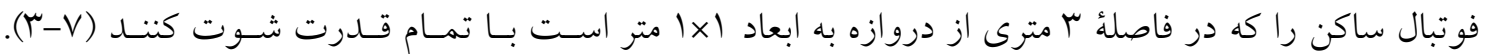

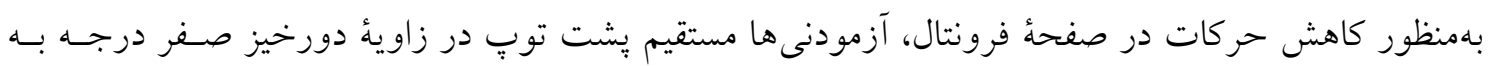

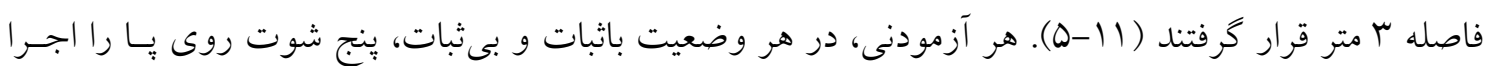

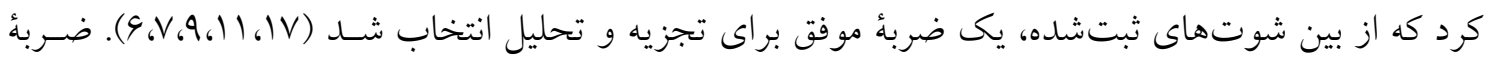

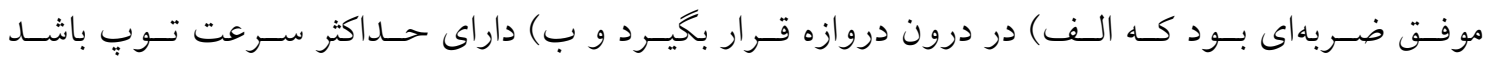

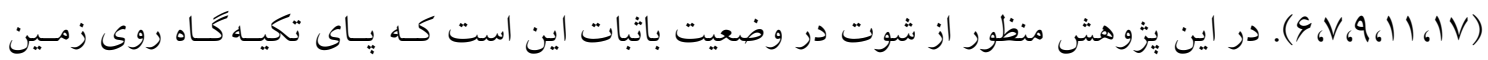
سفت قرار بخيرد (همانند حالت طبيعى)، درحالى كه شوت در وضعيت بىثباتى اين اسـت كـه بـاى تكيـهــاه

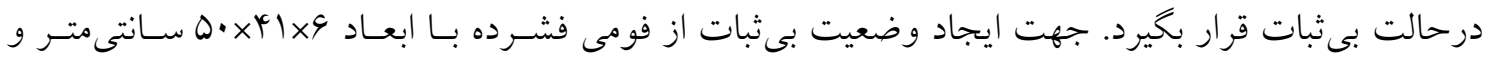
درجهُ سختى متوسط استفاده شد. انتخاب اين فوم براساس آزمون تعادلى بس (BESS) " بود كه از آن به مثابـــ 


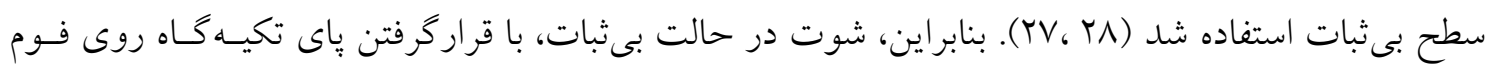
مذكور اجرا شد. دادههاى كينماتيكى جابهجايى زاويهاى و سرعت زاويهاى مفاصل ران، زانو و م-ج جــا در مراحـل FS، FT،

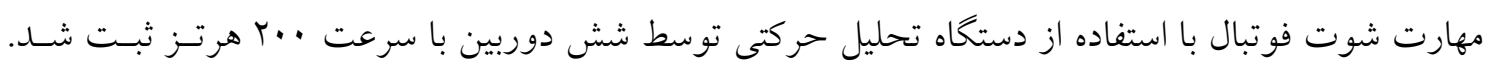
دوربينها بهنحوى مستقر شدند كه هر نشانكر توسط حداقل سه دوربين در محيط نرمافـزار CORTEX نسـخهُ

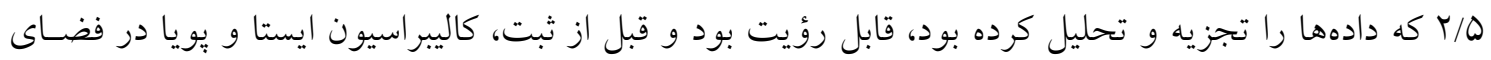

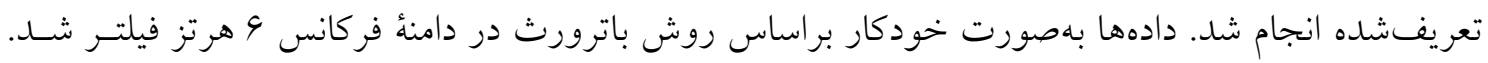

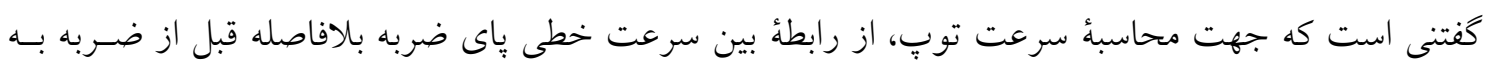
توبٌ، سرعت اولية توبٍ ارزيابى شد (1)، (1):

$$
V_{\text {(ball) }}=1.23 V_{\text {(foot) }}+2.72
$$

ضربهُ روى يا در تعريف مهارت كامل داراى جهار مرحله است: الف) باز شدن يا هنَام نوسان به عقـب، ب)

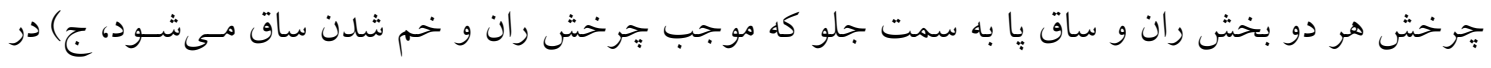

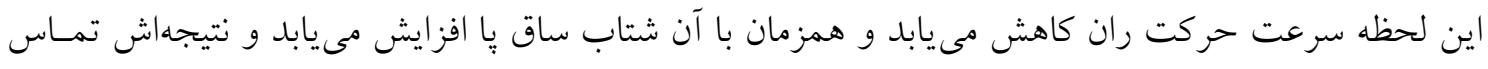

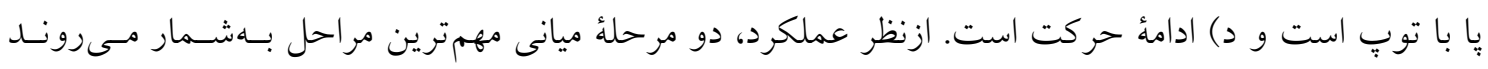

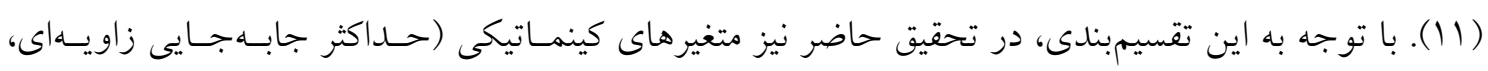

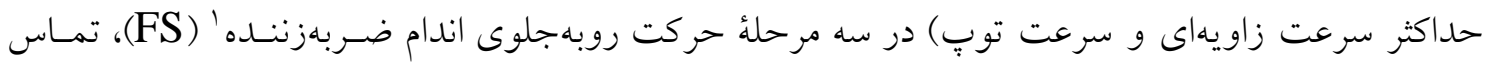

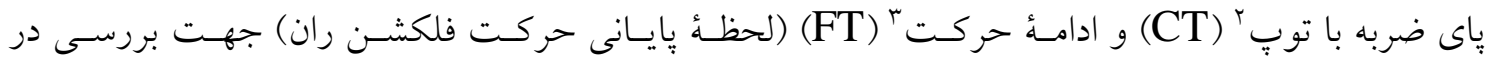

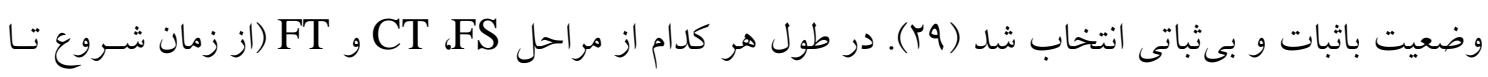
زمان بايان همان مرحله)، حداكثر جابهجايى زاويهاى (درجه) و حداكثر سرعت زاويهاى (درجه بــر ثانيسه) در هر مفصل بهلطور جداكانه محاسبه و ارائه شد (4-4). همجنين، كفتنى است كه براى سهولت بيشتر در تفسير

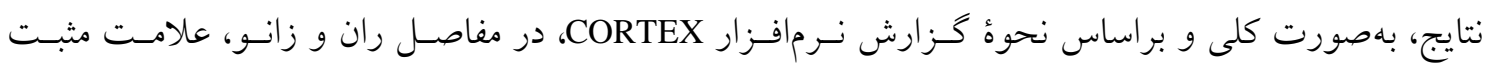

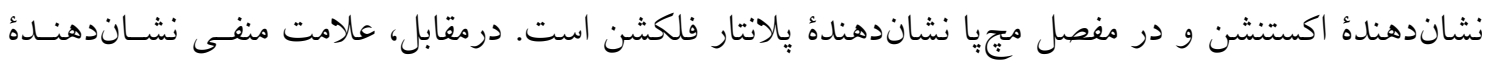

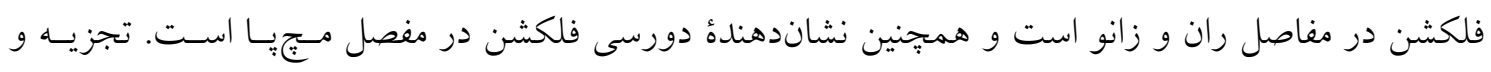

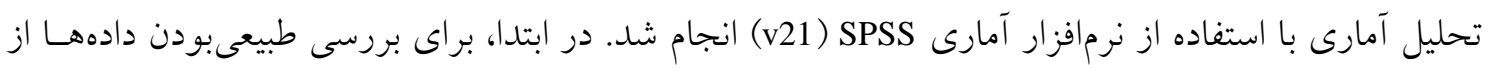

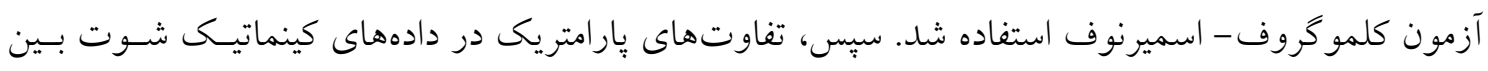

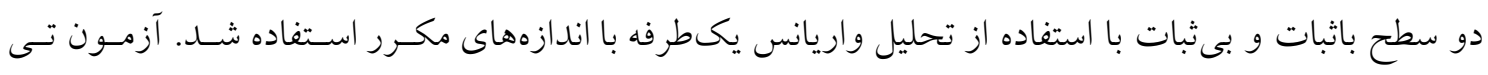

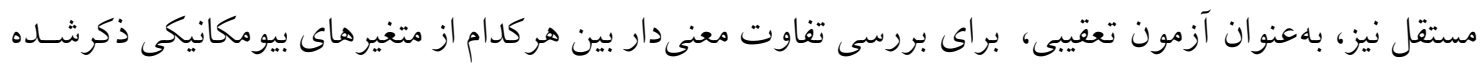

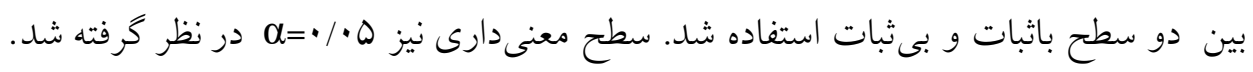




\section{بافتهها}

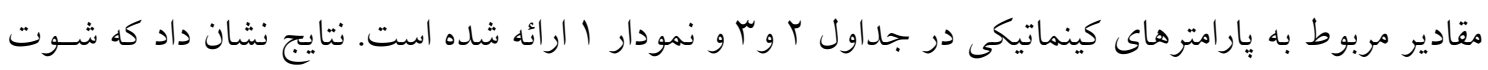

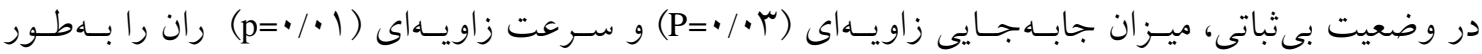
معنادارى كاهش مىدهد. در زمان شوت در وضعيت بىثبات، ران در لحظةٌ تماس، زاويـهُ اكستنشـن بيشـترى

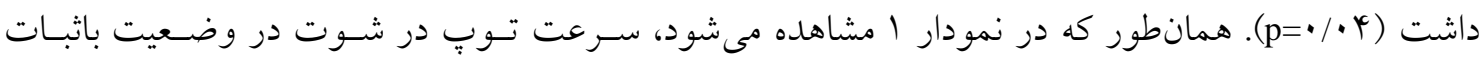

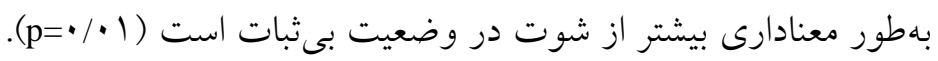

جدول r. مقايسه ميانگين و انحر اف معيار پارامترهاى حداكثر جابهجايى زاويهاى شوت روى دو سطح باثبات و بىثبات (علامت مثبت نشاندهندة

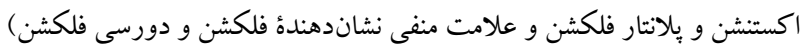

\begin{tabular}{|c|c|c|c|c|c|c|}
\hline $\begin{array}{c}\text { Effect } \\
\text { Size }\end{array}$ & P-Value & سطح بىثبات & سطح باثبات & مفاصل & ل يارامتر & لحظه \\
\hline$\cdot / 09$ & $* \cdot / \cdot r$ & $-9 Q / Y Y \pm V$ & $-V 1 / 99 \pm 9 / 99$ & ران - ت ت ان & \multirow{3}{*}{ حاواكثر جابهجايى (درجه) } & \multirow{3}{*}{ FS } \\
\hline.$/ 14$ & $\cdot / \pi 1$ & $01 / 9 \cdot \pm 14 / \pi$ & YN/YYIIY/VG & زانو & & \\
\hline$\cdot / \cdot r$ & $\cdot / M \Lambda$ & $-I r / 9 \Delta \pm \Lambda / \Delta r$ & $-\mid Y / 9 V \pm 9 / \Delta V$ & مْج & & \\
\hline$\cdot \mu_{Y}$ & $* \cdot / \cdot \varphi$ & $\mid r \cdot / \Lambda \wedge \pm \Delta / r \Delta$ & IKY/NTEV/OG & 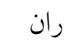 & \multirow{3}{*}{ زاويه (درجه) } & \multirow{3}{*}{ CT } \\
\hline س & $.1 \cdot 9$ & $119 / \cdot 0 \pm 1 \cdot / 11$ & $11 r / 4 r \pm V / 99$ & زانو & & \\
\hline.$/ \cdot r$ &.$/ 01$ & $1 r \Delta / \Delta \wedge \pm 9 / N T$ & $154 / \Delta 9 \pm 9 / 9 q$ & مجّ & & \\
\hline.$/ \cdot 1$ &.$/ 91$ & $-Q Y / Y T \pm 19 / \cdot 0$ & 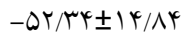 & ران - ت ت ان & \multirow{3}{*}{ حداكثر جابهجايى } & \multirow{3}{*}{ FT } \\
\hline$\cdot / r$. &.$/ M$ & $0 V / / 9 \pm 9 / 99$ & $G T / 1 \cdot \pm 9 / \mu r$ & زانو & & \\
\hline.$/ \cdot 1$ & . NG & $-\cdot / \Delta \wedge \pm r \Psi / / \Lambda$ & $-Y / \Lambda \Delta \pm Y r / \Psi$. & مَج & & \\
\hline
\end{tabular}

r. مقايسه ميانگين و انحر اف معيار بارامترهاى حداكثر سرعت زاويهاى شوت روى دو سطح باثبات و بىثبات جدول

\begin{tabular}{|c|c|c|c|c|c|c|}
\hline $\begin{array}{l}\text { Effect } \\
\text { Size }\end{array}$ & P- Value & سطح بىثبات & سطح باثبات & مفاصل & يار امتر & لحظه \\
\hline$\cdot / 4$. & $* \cdot / \cdot 1$ & $Q T Q / T 0 \pm 1 / T / Q 9$ & $1 \cdot 1 \cdot 11 \cdot \pm 101 / 90$ & 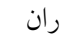 & \multirow{3}{*}{ حداكثر سرعت } & \multirow{3}{*}{ FS } \\
\hline$\cdot / \cdot r$ & $\cdot / A^{4}$ & $10 V Q / \mathcal{G H} \pm Y Y Y / 11$ & $191 \% / 0 \pm r V V / I V$ & 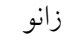 & & \\
\hline$\cdot / \cdot 1$ & $\cdot / \mathrm{VA}$ & $\| \Lambda / \Lambda \Lambda \pm V Y \psi / 1 \Lambda$ & $0 . / 19 \pm \wedge \Delta 9 / .9$ & مْج & & \\
\hline.$/ \cdot r$ & $\cdot / 44$ & $-94 / 49 \pm 19 \cdot / 0$. & $-\Lambda \psi / \backslash \Lambda \pm \mid \psi r / Y \psi$ & 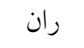 & \multirow{3}{*}{ (درجه بر ثانيه) } & \multirow{3}{*}{$\mathrm{CT}$} \\
\hline.$/ \cdot 1$ & $\cdot / 9$ & $19 Y Q / r \Lambda \pm F r V / \cdot r$ & $19 r \cdot / 9 \Lambda \pm r \Delta \Lambda / 9 V$ & زانو & & \\
\hline$\cdot / \cdot \wedge$ & $\cdot / 1 \wedge$ & $1 F \mu \Lambda / \mu Y \pm \Delta \psi \Lambda / \cdot \Lambda$ & $|\Gamma| \Lambda / \Gamma^{\prime} \Phi \pm V Q \mid / Y \Lambda$ & مج & & \\
\hline$\cdot / \cdot r$ & $\cdot / \mu \wedge$ & $9 V \backslash / 1 \Lambda \pm 19 Y / 4 Y$ & $99 \% / 04 \pm 19.190$ & 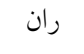 & \multirow{3}{*}{ حداكثر سرعت } & \multirow{3}{*}{ FT } \\
\hline$\cdot / \cdot 0$ & $\cdot \mu \cdot$ & IYGY/GYEYMT/NT & $|r| N / \cdot r \pm T V Q / r \mid$ & زانو & & \\
\hline .1 .9 & $\cdot / T Y$ & $-1 Y<q / V Y \pm 11 Y \sigma / 11$ & $-|r T r / \Delta T \pm 9 \Lambda 1 / \pi|$ & مْنج & & \\
\hline
\end{tabular}




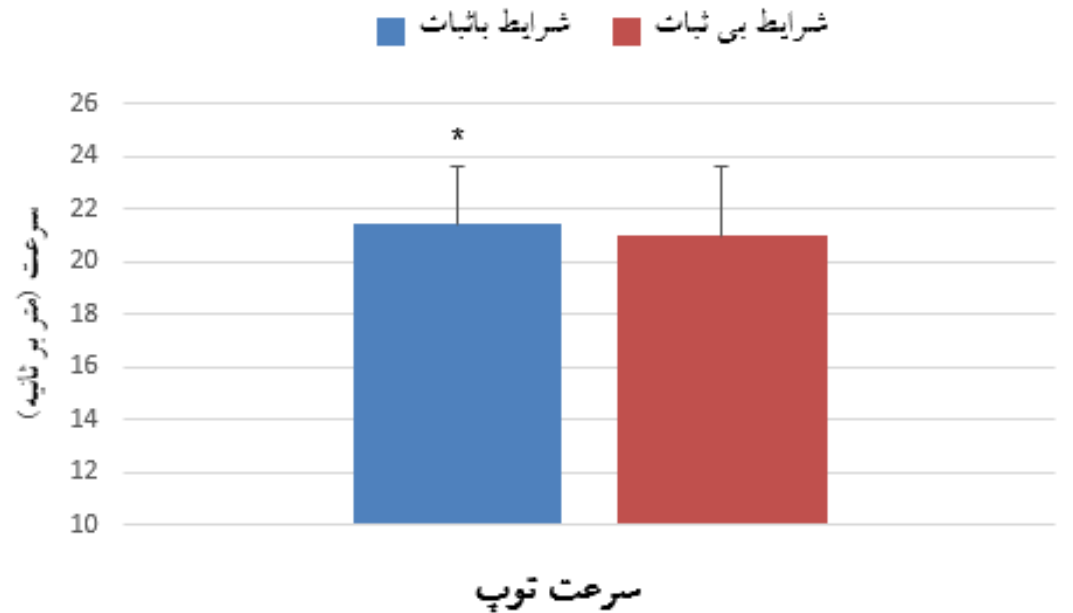

نمودار ا. مقايسه ميانگين و انحر اف معيار سرعت توٍٍ شوت روى دو سطح باثبات و بىثبات. سرعت توبٍ بهدنبال وضعيت باثبات، بهصورت معنى

هدف تحقيق حاضر، بررسى تأثير سطح نايايدار پِاى تكيه كاه بر كنيماتيك شـوتِ روى پــاى بازيكنـان فوتبـال

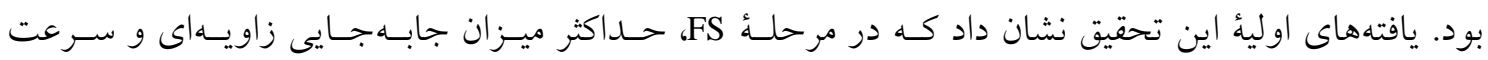
زاويهاى ران بهطور معنى دارى در شوت با وضعيت باثبات بيشتر از وضعيت بىثبـات بـود. امـا بـين حسـاكثر

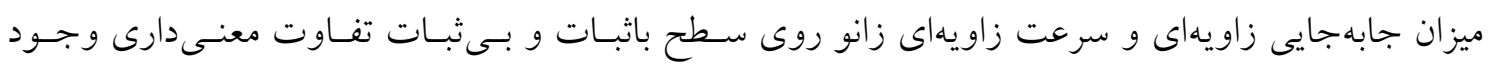

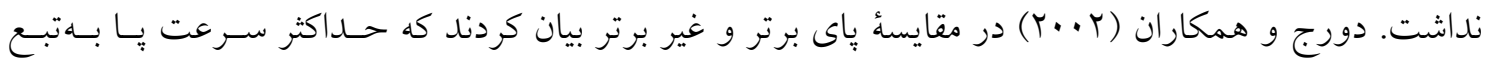
سرعت ساق است كه اين سرعت نيز ناشى از سرعت زاويهاى ران است. بازيكنان مرد در مقايسه با بازيكنـان

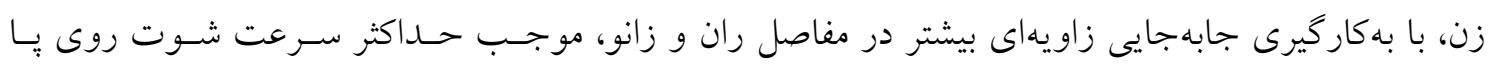

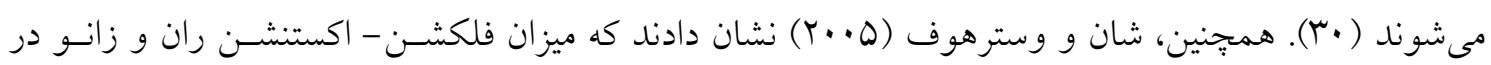

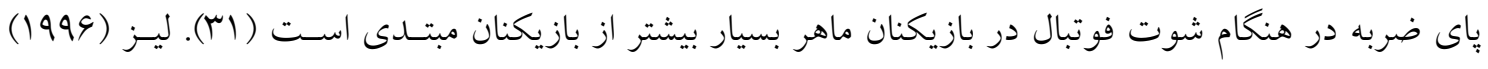

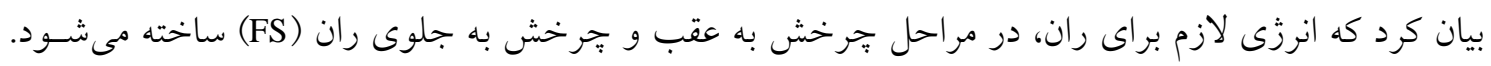

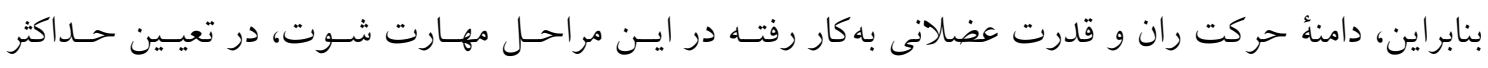

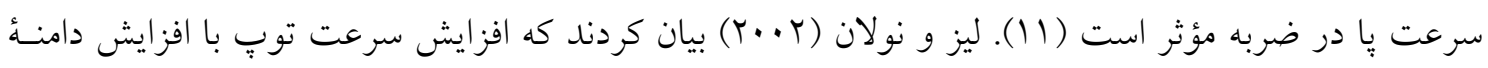
حركت در ران و افزايش سرعت زاويـهاى ران و سـاق در ارتبـاط اسـت (Tr). رابـرتس و متكـالف (1991)

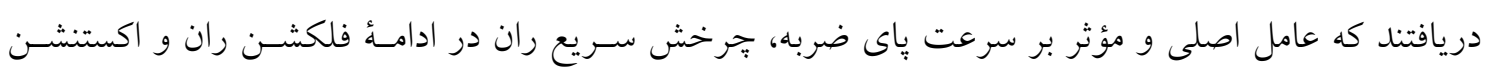
زانو است (سT). براساس نتايج تحقيقات كذشته و با توجه به نتايج يزوهش حاضر، مى توان بيان كرد كه دامنه حركتى و سرعت زاويهاى مفصل ران در مرحله FS در طول شوت روى سطح باثبـات، داراى نمـرهُ بيشـتر و معنى دارى نسبت به بارامتر مشابه خودش در طول شوت روى سطح بىثبات بود، بنـابراين، از عوامـل تعيسين

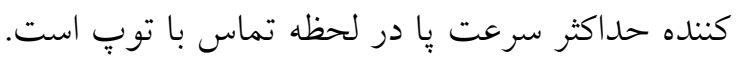


در لحظة CT، ميزان فلكشن ران و زانو در شوت روى سطح باثبات بيشتر از سطح بىثبات بود، ولسى تفـاوت

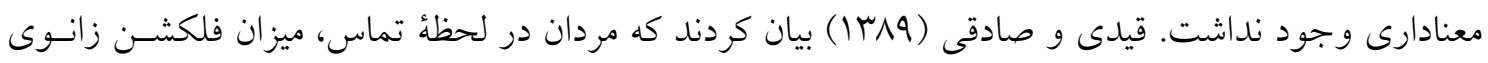

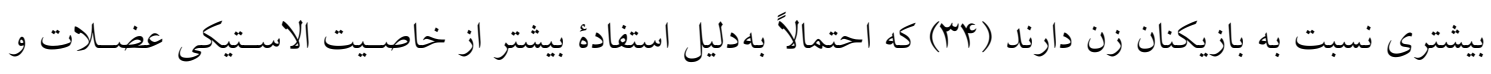

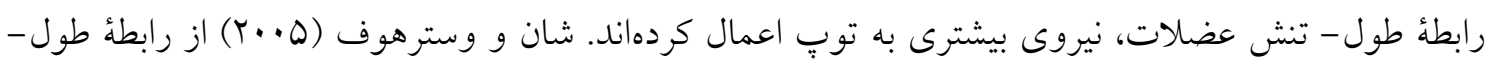

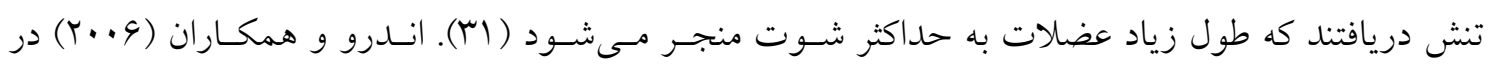

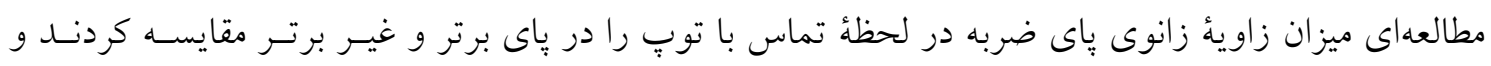

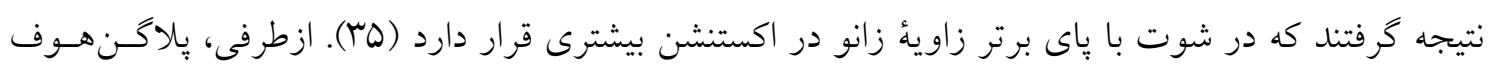

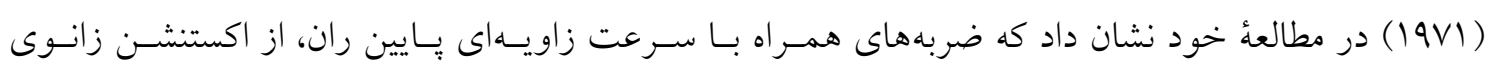

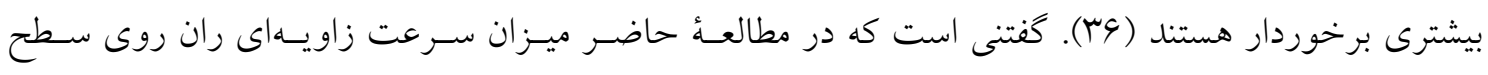
باثبات بيشتر از سطح بىثبات بود، درحالى كه ميزان اكستنشن زانو در شوت روى سطح بـى بنبات بيشتر بود، كه

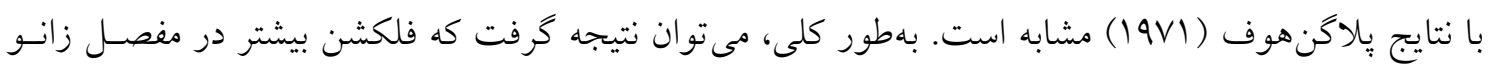

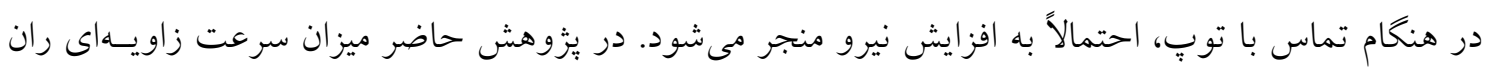

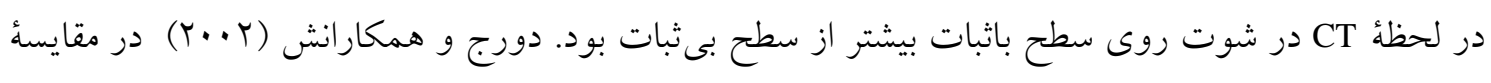

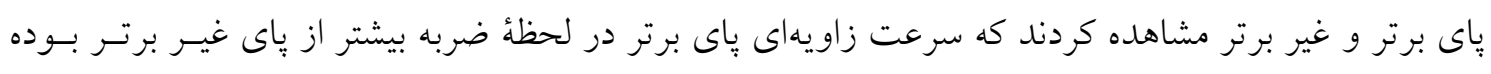

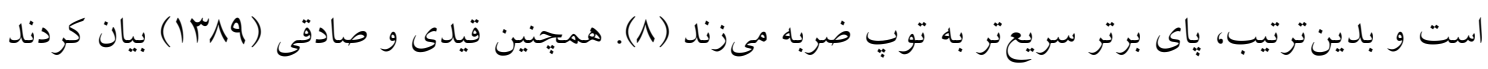

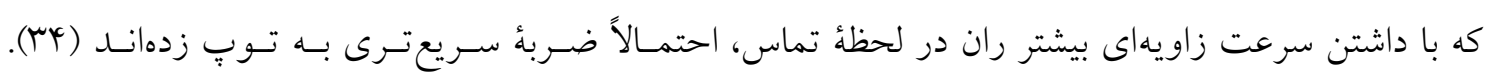

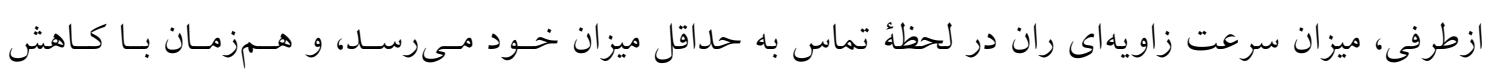

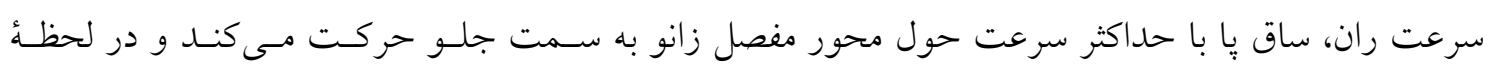

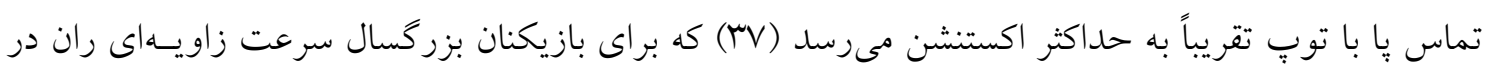

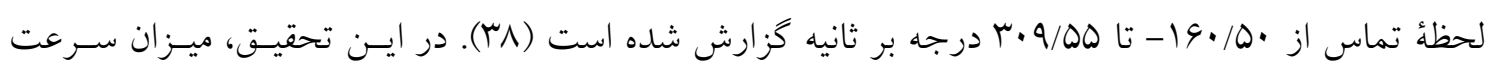

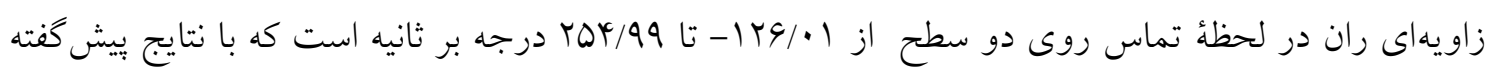
مطابقت دارد. يكى از معيارهايى كه در بسيارى از مطالعات عامل تعيين كننده موفقيت در اجراى شوت در نظر كرفته شـده،

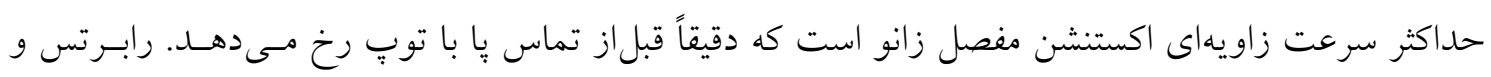

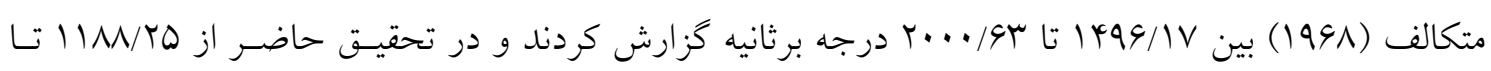

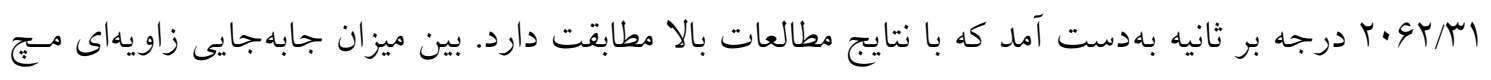
يا در طول شوت روى يا روى سطح باثبات و بىثبات تفاوت معنـادارى وجــود نداشـت. شـان و وسـترهوف

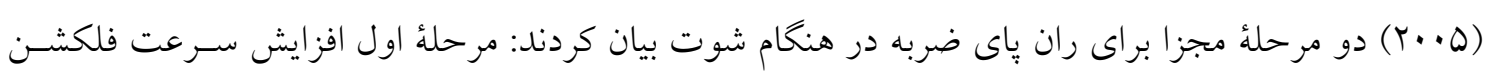

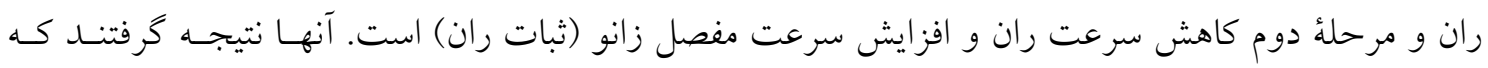

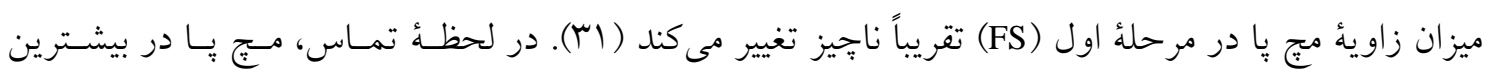




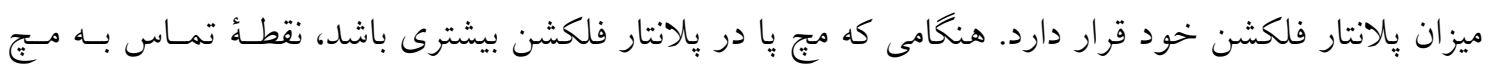

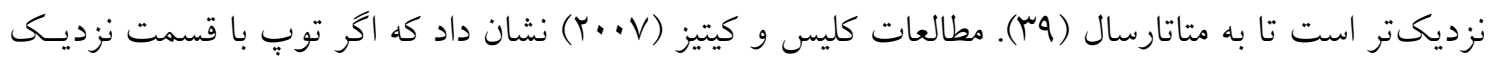

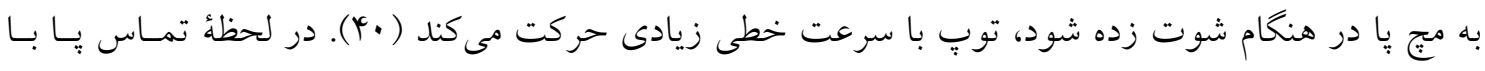

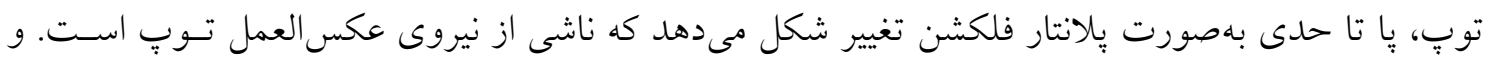
اين تغيير زاويه در زمانى بسيار اندى رخخ مى دهد كه باعث سرعت زاويهاى يلانتار مى شود ( الب، • (1). قيـدى و

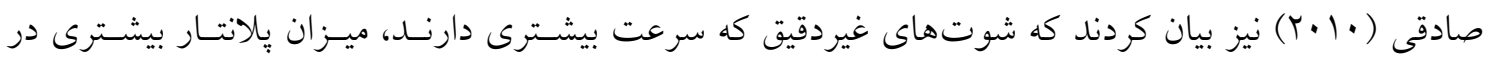

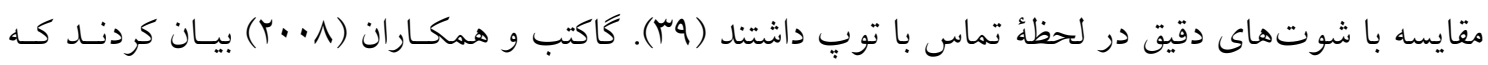

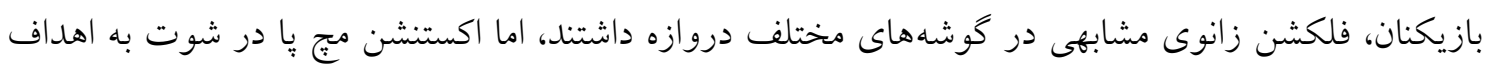

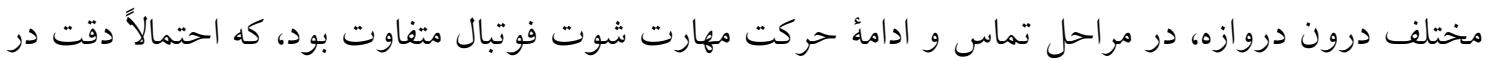

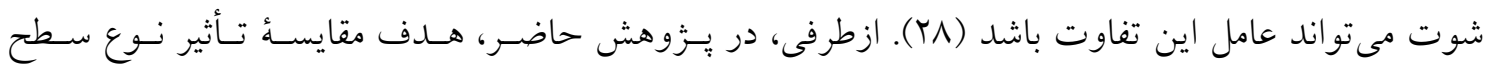

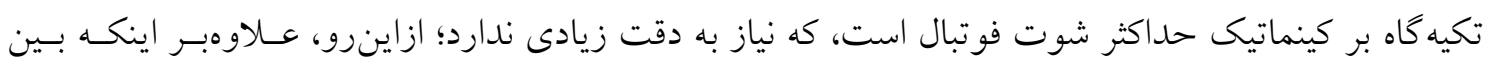
ميزان فلكشن زانو در لحظةٌ تماس روى سطح باثبات و بى ثبـات تفـاوت معنـادارى مشـاهده نشـاه، در ميـزان

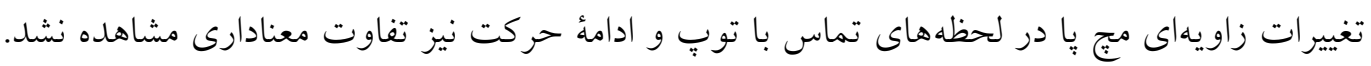
در مرحلة ادامهٔ حركت (FT) سرعت زاويهاى ران و زانو در شوت روى سطح باثبات بيشتر از سطح بسىثبـات بود، اما در سطح معنادار تفاوتى مشاهده نشد. اين مرحله بهمنظور حذف تدريجى نيروهاى حاصـل از نوسـان

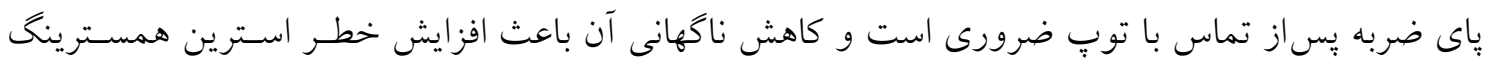

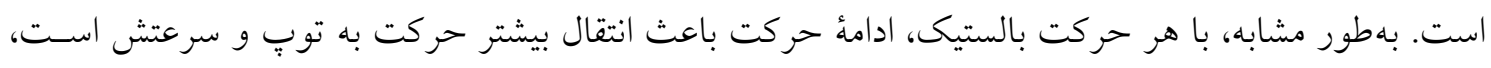

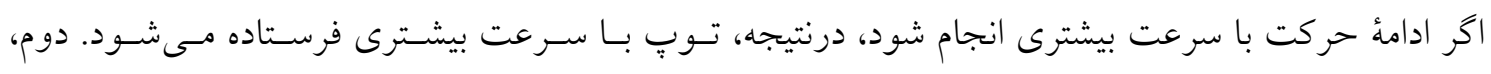

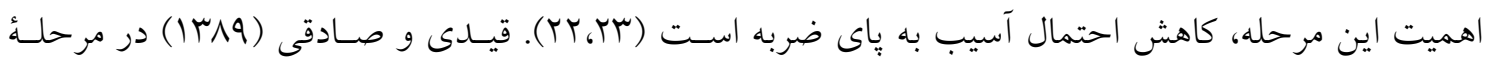

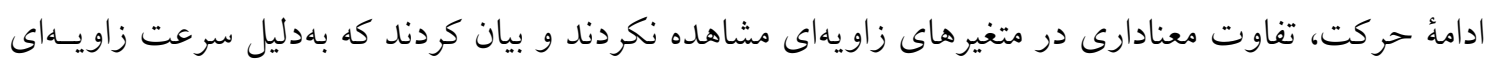

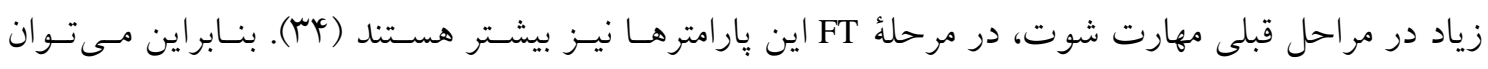

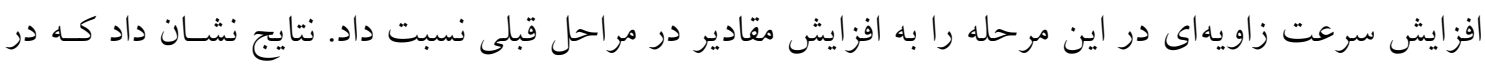

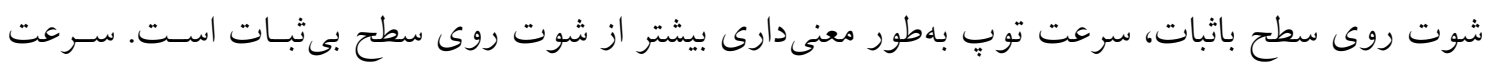

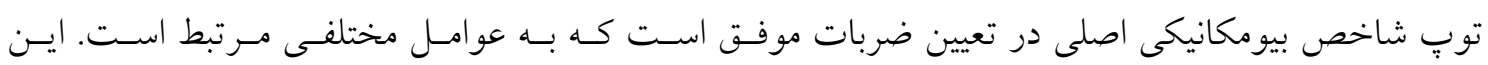

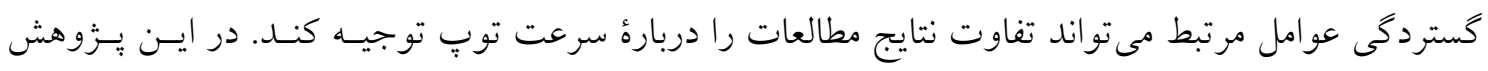

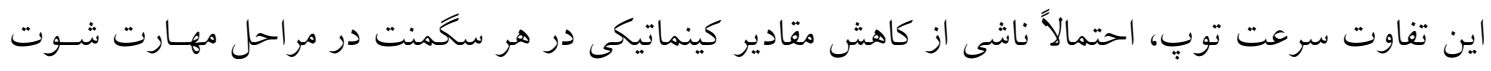

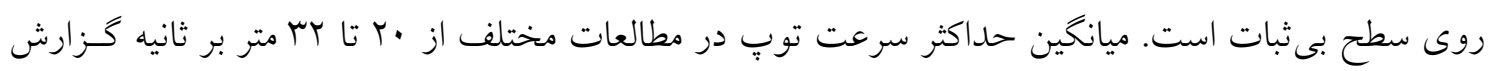

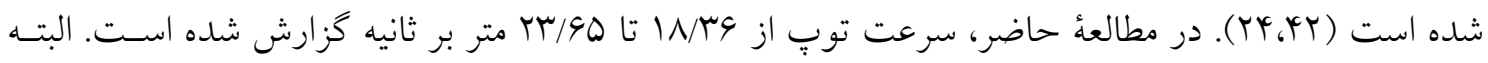

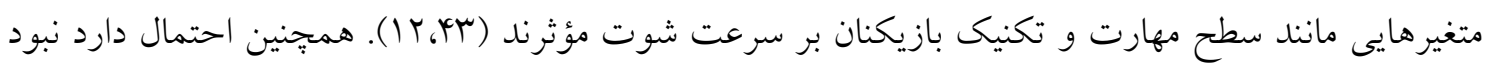




$$
\begin{aligned}
& \text { امكان ايجاد حالوهواى واقعى فوتبال در محيط آزمايشخاهى و همجٍنـين تفـاوت در ميـزان مسـافت و زاويـــ } \\
& \text { دورخيز بر عملكرد آزمودنىها تأثير كذاشته باشد. }
\end{aligned}
$$

براساس نتايج يزوهش حاضر، سطح نايايدار بر برخى متغيرهاى كينماتيكى شوت روى يا اثر معنسىدارى دارد.

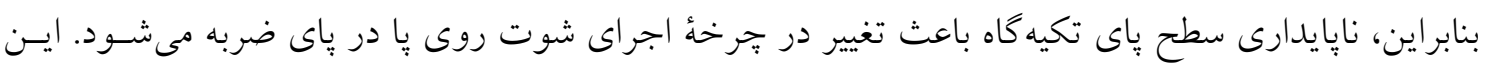
تغيير موجب كاهش مقادير كينماتيكى در مرحلة اول مهارت شوت ياى ضـربه مسى شـود كـهـ براسـاس اصـل هماهنگى بين سخمنت ها و مفاصل، درنهايت به كاهش سرعت توبٍ منجر مىشود.

نويسند گان مقاله از تمام آزمودنىها و عزيزانى كه در اجراى اين تحقيق مـا را يـارى كردنـد، كمـال تشـكر و قدردانى را دارند.

\section{منابع}

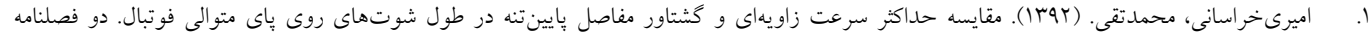

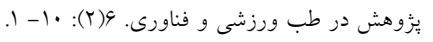

2. Amiri-Khorasani, M., AbuOsman, N.A., Yusof, A. (2009). Biomechanical responses of Instep kick between different positions in professional soccer players. Journal of Human Kinetics. 22 :21-7.

3. Amiri-Khorasani, M., Abu Osman, N.A., Yusof, A. (2011). Acute effect of static and dynamic stretching on hip dynamic range of motion (DROM) during instep kicking in professional soccer players. Journal of Strength Conditioning Research. 25(4): 1177-81.

4. Amiri-Khorasani, M., Abu Osman, N.A., Yusof, A. (2010). Electromyography assessments of the vastus medialis muscle during soccer instep kicking between dynamic and static stretching. Journal of Human Kinetics. 24: 35-42.

5. Amiri-Khorasani M. (2014). Acute effects of different stretching methods on static and dynamic balance in female soccer players. International Journal Therapy Rehabilititation, in press.

6. Amiri-Khorasani M., Ferdinand, R. (2014). Kinematics assessment of soccer instep kicking in less and more experienced players; between different acute stretching methods. Journal of Sports Technology, in press.

7. Amiri-Khorasani M., Kellis, F. (2013). Static vs. dynamic acute stretching effect on quadriceps muscle activity during soccer instep kicking. Journal of Human Kinetics. 38: 37-47.

8. Dorge, H.C., Andrsen, T.B., Sorensen, H., Simonsen, E.B. (2002). Biomechanical differences in soccer kicking with the preferred and non- preferred leg. Journal of Sports Sciences. 20: 293-9.

9. Nunome, H., Ikegami, Y., Kozakai, R., Apriantono, T., Sano, S. (2006). Segmental dynamics of soccer instep kicking with the preferred and non- preferred leg. Journal of Sports Sciences. 24: 529-41.

10. Shinkai, H., Nunome, H., Isokawa, M., Ikegami, Y. (2009). Ball impact dynamics of instep soccer kicking. Medicine Science and Sports Exercise. 41(4): 889-97.

11. Lees, A. (1996). Biomechanics applied to soccer skills. In: Science and Soccer. Ed: Reilly, T. London: E \& FN Spon. 123-33.

12. Lees, A., Nolan, L. (1998). The biomechanics of soccer: A review. Journal of Sports Sciences. 16: 211-34.

13. Oyama, S., Myers, J.B., Wassinger, C.A., Ricci, D., Lephart, S.M. (2008). Asymmetric resting scapular posture in healthy overhead athletes. Journal of Athletic Training: 43(6): 565-70.

14. Barone, R., Macaluso, F., Traina, M., Leonardi, V., Farina, F. Di Felice, V. (2011). Soccer players have a better standing balance in nondominatnt one-legged stance. Journal of sport Medicine. 2:1-6.

15. Rodano, R., Cova, P., Vigano. R. (1988). Designing a football boot: a theoretical and experimental approach. In: Science and Football, T. Reilly, A. Lees, K. Davids, and W. Murphy (Eds.). London: E \& FN Spon. 416-25.

16. Kermond, J., Konz. S. (1978). Support leg loading in punt kicking. Res. Q. 49:71-9.

17. Kellis, E., Katis, A., Gissis, I. (2004). Knee biomechanics of the support leg in soccer kicks from three angles of approach. Medicine and Science in Sports and Exercise. 36: 1017-28.

18. Hosford G., Meikle, D. (2007). The science of kicking, Upper Ferntree Gully, Melbourne, B.I.P.E. Publications.

19. Hrysomallis, C., MCLaughlin, P., Goodman, C. (2006). Relationship between static and dynamic balance tests among elite Australian Footballers. Journal of Science and Medicine in Sport. 9(4): 288-91.

20. Chew-Bullock, T.S., Anderson, D.I., Hamel, K.A., Gorelick, M.L., Wallace, S.A., Sadaway, B. (2012). Kicking performance in relation to balance ability over the support leg .Human Movement Science. 31(6): 1615-23.

21. Katis, A., Giannadakis, E., Kannas, T., Amiridis, I., Kellis, E., Lees, A. (2013). Mechanisms that influence accuracy of the soccer kick. Journal of Electromyography and Kinesiology. 23: 125-31.

22. Barfield, W.R. (1998). The biomechanics of kicking in soccer. Clinics in Sports Medicine. 4: 711-27. 
23. Goktepe, A., Karabork, H., Ak, E., Cicek, S., Korkusuz, F. (2008). Kinematic analysis of penalty kick in soccer. J. Fac.Eng.Arch. Selcuk Univ. 23(3): 45-9.

24. Andersen, T.B., Dorge, H., Thomsen, F. (1999). Collision in soccer kicking. Sports Engineering. 2: 121-5.

25. Schmitz R.J., Arnold, B. (1998). Intertester and Intratester reliability of a dynamic balance protocol using the biodex stability system. Journal of Sport Rehabilitation. 7: 95 -101.

26. Rozzi, S.L., Lephart, S.M., Gear, W.S., Fu, F.H. (1999). Knee joint laxity and neuromuscular characteristics of male and female soccer and basketball players. The Amrican Journal of Sports Medicine. 27(3): 312-19.

27. Bressl, E., Yonker, J.C., Kras, J., Heath, E.M. (2007). Comparison of static and dynamic balance in female collegiate soccer, basketball and gymnastics athletes. Journal of Athlete training. 42(1): 42-6.

28. Riemann, B.L., Guskiewicz, K.M., Shields, E.W. (1999). Relationship between clinical and forceplate measures of postural stability. Journal of Sport Rehabilititation. 8:71-82.

29. Goktepe, A., Karabork, H., Ak, E., Cicek, S., Korkusuz, F. (2008). Kinematic analysis of penalty kick in soccer. J. Fac.Eng.Arch. Selcuk Univ, 23: 45-9.

30. Tant, C.L., Browder, K.D., Wilkerson, J.D. (1991). A three dimensional kinematic comparison of kicking techniques between male and female soccer players. In Biomechanics in Sport IX.101-5.

31. Shan, G., Westerhoff, W. (2005). Full-body kinematic characteristics of the maximal instep kick by male soccerplayers and parameters related to kick quality. Sports Biome-chanics. 4: 59-72.

32. Lees, A., Nolan, L. (2002). 3D kinematic analysis of the instep kick under speed and accuracy conditions, in Science and Football IV (eds W. Spinks, T. Reilly and A. Murphy), E \& FN Spon, London. 16-21.

33. Roberts, E.M., Metcalf, A. (1968). Mechanical analysis of kicking. In Biomechanics I (edited by J. Wartenweiller, E. Jokl and M. Hebbelink). 315-9.

$$
\text { ry }
$$

35. Andrew, J.H., Mannering, A. (2006). A biomechanical analysis of the instep kick in soccer with preferred and non- preferred foot. XXIV ISBS Symposium 2006, Salzburg - Austria.

36. Plagenhoef, S. (1971). Patterns of human motion. Englewood Cliffs, NJ: Prentice-Hall.

37. Wickstrom, R.L. (1975). Developmental kinesiology. Exercise and Sports Science Reviews. 3: 163-92.

38. Putnam, C.A. (1991). A segment interaction analysis of proximal-to-distal sequential segment motion patterns. Medicine and Science in Sports and Exercise. 23: 130-44.

39. Gheidi, N., Sadeghi, H. (2010). Kinematic comparison of successful and unsuccessful instep kick in indoor soccer. American Journal of Applied Sciences. 7(10): 1334-40.

40. Kellis, E., Katis, A. (2007). Biomechanical characteristics and determinants of instep soccer kick. Journal of Sports Science and Medicine. 6: $154-65$.

41. Asami, T., Nolte, V.(1983). Analysis

(1983). Analysis of powerful ball kicking. In: Biomechanics VIII-B. Eds: Matsui, H. and Obayashi, K. Champaign IL: Human Kinetics. 695-700.

42. Katis, A.T., Kellis, E. (2010). Three- dimensional kinematics and ground reaction forces during the instep and outstep soccer kicks in pubertal players. Journal of Sports Science. 28(11): 1233-41.

43. Orloff, H., Sumida, B., Chow, J., Habibi, L., Fujino, A., Kramer, B. (2008). Ground reaction forces and kinematics of plant leg position during instep kicking in male and female collegiate soccer players. Sports Biomechanics. 7(2): 238-47. 